\title{
DIFERENÇAS E SEMELHANÇAS NA POSITIVAÇÃO DE DEVERES FUNDAMENTAIS NO CONSTITUCIONALISMO ESPANHOL E BRASILEIRO: DIÁLOGO ENTRE FRANCISCO RUBIO LLORENTE E O GRUPO DE PESQUISA "ESTADO, DEMOCRACIA E DIREITOS FUNDAMENTAIS"
}

\author{
DIFFERENCES AND SIMILARITIES IN THE POSITION OF \\ FUNDAMENTAL DUTIES IN SPANISH AND BRAZILIAN \\ CONSTITUTIONALISM: DIALOGUE BETWEEN FRANCISCO RUBIO \\ LLORENTE AND THE RESEARCH GROUP "STATE, DEMOCRACY AND \\ FUNDAMENTAL RIGHTS"
}

\section{Anselmo Laghi Laranja ${ }^{1}$ Adriano San'Ana Pedra ${ }^{2}$ Daury Cesar Fabriz ${ }^{3}$}

\begin{abstract}
RESUMO: No presente artigo tem-se como objetivo analisar o texto "Los deberes constitucionales" de autoria de Francisco Rubio Llorente e comparar a análise feita pelo referido autor acerca dos deveres fundamentais na Constituição Espanhola de 1978 com a produção acadêmica do Grupo de Pesquisa "Estado, Democracia e Direitos Fundamentais" (GPEDDF) do Programa de Pós-Graduação Stricto Sensu da Faculdade de Direito de Vitória (FDV), que tem se dedicado ao estudo do deveres fundamentais na Constituição da República Federativa do Brasil de 1988. Dessa revisão bibliográfica foi possível identificar pontos de problematização e oportunidades de aprendizado a partir da experiência constitucional da Espanha e do Brasil.
\end{abstract}

\footnotetext{
${ }^{1}$ Doutor em Direitos e Garantias Fundamentais pela Faculdade de Direito de Vitória (FDV), mestre em História pela Faculdade Universal do Espírito Santo, graduado em Direito pela Faculdade de Direito de Colatina. Juiz de Direito do Tribunal de Justiça do Estado do Espírito Santo. E-mail: anselmolaranja@gmail.com.

2 Doutor em Direito do Estado pela Pontifícia Universidade Católica de São Paulo (PUC/SP), mestre em Direitos e Garantias Fundamentais pela Faculdade de Direito de Vitória (FDV) e em Física Quântica pela Universidade Federal do Espírito Santo (UFES). Professor de Direito Constitucional da Faculdade de Direito de Vitória (FDV). E-mail: adrianopedra@fdv.br. ORCID: https://orcid.org/0000-0002-8174-9122.

${ }^{3}$ Doutor e mestre em Direito pela Universidade Federal de Minas Gerais. Presidente da Academia Brasileira de Direitos Humanos. Professor de Direito Constitucional da Faculdade de Direito de Vitória (FDV) e da Universidade Federal do Espírito Santo (UFES). E-mail: daury @ terra.com.br. ORCID: https://orcid.org/0000-0002-3781-5890
} 
Palavras-chave: Deveres fundamentais; Francisco Rubio Llorente; Grupo de Pesquisa "Estado, Democracia e Direitos Fundamentais"

ABSTRACT: This article aims to analyze the text "Los deberes constitucionales" written by Francisco Rubio Llorente and compare the analysis made by that author about the fundamental duties in the Spanish Constitution of 1978 with the academic production of the Research Group "Estado, Democracy and Fundamental Rights "(GPEDDF) of the Stricto Sensu Graduate Program of the Faculty of Law of Vitória (FDV), which has been dedicated to the study of fundamental duties in the Constitution of the Federative Republic of Brazil of 1988. From this bibliographical review it was possible identify problematization points and learning opportunities from the constitutional experience of Spain and Brazil.

Key-words: Fundamental duties; Francisco Rubio Llorente; State, Democracy and Fundamental Rights Research Group.

Sumário: 1. Introdução. 2. Deveres constitucionais, deveres aludidos pela constituição e deveres fundamentais. 3. Sistematização da produção acadêmica do grupo de pesquisa estado, democracia e direitos fundamentais. 4. Deveres constituicionais em sentido estrito possuem eficácia horizontal? 5. Existem deveres constitucionais autoaplicáveis? 6. Conclusão; 7. Referências.

\section{INTRODUÇÃO}

Há muito o tema dos deveres fundamentais estava eclipsado pelo fervor da academia na pesquisa e estudo dos direitos fundamentais, mas, como resultado natural dessas pesquisas, foi-se revelando a importância dos deveres fundamentais enquanto uma dimensão correlata do projeto de criação de sociedades formadas por pessoas livres e iguais: a responsabilidade.

Aos poucos, a temática dos deveres fundamentais tem ganhado mais importância na academia jurídica. Obras como as de Nabais (2002), Canotilho (2004), Dimoulis e Martins (2011), Peces-Barba Martínez (1987) e Lanchester (2010) são exemplos de produções que, gradualmente, têm auxiliado a destacar a importância que os deveres constitucionalmente positivados e dirigidos aos cidadãos possuem na consolidação do Estado Democrático de Direito.

O Grupo de Pesquisa "Estado, Democracia Constitucional e Direitos Fundamentais" (GPEDDF), vinculado ao Programa de Pós-Gradução Stricto Sensu 
da Faculdade de Direito de Vitória (FDV), vem, desde 2013, dedicando-se à temática dos deveres fundamentais. Esse Grupo atua, de forma resumida, em três frentes: (i) desenvolve pesquisas sobre a teoria dos deveres fundamentais, elaborando um arcabouço jurídico filosófico para compreender as características, funções, categorias e conceitos $^{4}$ que envolvem esses deveres; (ii) desenvolve pesquisa sobre deveres fundamentais em espécie, em que se correlacionam o conteúdo de teoria geral dos deveres com problemas concretos de deveres fundamentais específicos; (iii) desenvolve pesquisas comparativas para dialogar o conteúdo produzido pelo Grupo com aqueles elaborados por outros pesquisadores e centros de pesquisas do Brasil e do Mundo.

O presente artigo se alinha a terceira frente de produção de conteúdo do Grupo de Pesquisa, em que se seleciona, como produção acadêmica para diálogo, o texto "Los deberes constitucionales (1)", de autoria de Francisco Rubio Llorente e publicado em 2001 na "Revista Española de Derecho Constitucional".

Francisco Rubio Llorente é um dos grandes doutores em Direito Constitucional da Espanha. Dentre alguns aspectos da trajetória do jurista, pode-se destacar o título de Doutor honoris causa pela Universidade de Oviedo, o cargo de Vice-presidente do Tribunal Constitucional da Espanha e o de Secretário Geral do Congresso quando da promulgação da Constituição Espanhola em vigor (1978) (FREIJEDO, 1994, p. 7).

No artigo "Los deberes constitucionales (1)", Llorente apresenta traços distintivos de sua compreensão da teoria geral dos deveres fundamentais e apresenta considerações sobre alguns deveres fundamentais em espécie na Constituição Espanhola de 1978. Para os fins deste artigo, foram selecionadas duas ideias que

\footnotetext{
${ }^{4}$ Friza-se, nesse sentido, o conceito de deveres fundamentais elaborado pelo grupo, nos seguintes termos: "Dever fundamental é uma categoria jurídico-constitucional, fundada na solidariedade, que impõe condutas proporcionais àqueles submetidos a uma determinada ordem democrática, passíveis ou não de sanção, com a finalidade de promoção de direitos fundamentais" (GONÇALVES; FABRIZ, 2013, p. 92).
} 
serão contrapostas à produção do Grupo de Pesquisa Estado, Democracia e Direitos Fundamentais: (i) a eficácia vertical e horizontal dos deveres fundamentais e (ii) a possibilidade ou não de existirem deveres fundamentais autoaplicáveis.

Assim sendo, utiliza-se o método de revisão de literatura para explicar o posicionamento de Llorente e da literatura produzida pelo Grupo de Pesquisa e, dessa forma, compará-los de forma crítica. Em resumo, objetiva-se responder à seguinte pergunta: em que se assemelham e se diferenciam as perspectivas professadas no texto de Llorente e a produção do Grupo de Pesquisa da FDV?

A apresentação dos resultados alcançados é exposta em quatro capítulos. No primeiro, faz-se uma apresentação dos conceitos relevantes do artigo de Llorente e do conceito de dever fundamental do Grupo de Pesquisa Estado, Democracia Constitucional e Direitos Fundamentais. No segundo, sistematiza-se a produção acadêmica do Grupo de Pesquisa publicada em periódicos especializados e livros. No terceiro, realiza-se a comparação entre as posições de Llorente e do Grupo sobre a eficácia vertical e horizontal dos deveres fundamentais. No quarto, aborda-se o tema da existência ou não de deveres autoaplicáveis. Ao final, conclui-se com uma compilação das ideias construídas nos capítulos anteriores.

\section{DEVERES CONSTITUCIONAIS, DEVERES ALUDIDOS PELA CONSTITUIÇÃO E DEVERES FUNDAMENTAIS}

O texto "Los deberes constitucionales (1)" pode ser divido em duas partes. A primeira é relativa à teoria geral de deveres fundamentais, professada por Llorente a partir da realidade do constitucionalismo espanhol. A segunda refere-se a uma análise de deveres constitucionais em espécie, conforme constam na Constituição Espanhola de 1978.

$\mathrm{Na}$ primeira parte do artigo, Llorente apresenta três conceitos de deveres presentes na Constituição Espanhola de 1978: deveres constitucionais, deveres 
aludidos pela Constituição e deveres fundamentais. Esses conceitos podem ser comparados com aquele produzido pelo Grupo de Pesquisa "Estado, Democracia Constitucional e Direitos Fundamentais".

O autor (LLORENTE, 2001, p. 13-15) explica que "deveres constitucionais" é uma expressão consagrada na literatura especializada espanhola para designar as normas constitucionais que contém termos relativos a deveres. São exemplos as expressões "devem”, "deve”, "tem o dever" e demais equivalentes. Além disso, a academia jurídica espanhola também tem identificado como deveres constitucionais aquelas normas que não estão explícitas no texto, mas impõem condutas decorrentes da necessidade de efetivação dos direitos fundamentais.

Llorente (2001, p. 16) considera que essa abordagem dada pelos tribunais e pela literatura especializada saturou de tal forma a ideia de deveres fundamentais que ela se tornou uma categoria juridicamente irrelevante. Ter-se-ia elaborado um instituto composto por elementos tão distintos que a ideia de "deveres constitucionais" não traz nenhuma utilidade na resolução de problemas de interpretação.

Por conta disso, propõe-se que se trabalhe com um conceito que seja mais defensável teoricamente, bem como que se aperfeiçoe o modo como os magistrados e legisladores têm utilizado os enunciados de deveres fundamentais (LLORENTE, 2001, p. 16-17). Com esse objetivo, Llorente explica a primeira distinção a ser feita: aquela referente a deveres constitucionais e deveres aludidos na Constituição.

Dentre todos os enunciados da Constituição Espanhola que se utilizam de expressões que vinculam imperativos (deveres aludidos na Constituição), seria possível distinguir aqueles "deveres em sentido estrito", que se caracterizam por possuírem uma existência autônoma em relação aos direitos fundamentais e às competências concretamente estabelecidas de órgãos de poder (LLORENTE, 2001, p. 17-18).

É baseado nessa ideia de "deveres em sentido estrito" que Llorente 
fundamenta seu conceito de deveres constitucionais. Segundo ele,

é absurdo considerar deveres constitucionais aqueles que existem como simples correlatos dos direitos fundamentais alheios, ou como mero limites internos deles, ou como consequência da sujeição específica a órgãos concretos de poder [tradução livre] ${ }^{5}$ (LLORENTE, 2001, p. 17$18)$.

Assim, deveres constitucionais passam a ser conceituados conforme imposições frente ao Estado enquanto elementos do "status geral de sujeição ao poder" (LLORENTE, 2001, p. 18). Com isso quer-se dizer que não derivam da competência atribuída a um determinado órgão (como o dever de respeitar as decisões prolatadas pelo Poder Judiciário, por exemplo).

A autonomia em relação a normas de direitos fundamentais ou de competências não é desvinculada das finalidades constitucionais. Por mais que qualquer obrigação (em sentido lato) tenha como fundamento de validade último a Constituição e, por isso, precise ser compatível com a finalidade de promoção de direitos fundamentais, os deveres constitucionais funcionam como explicitações que permitem a imposição de condutas necessárias à convivência democrática, que não podem ser diretamente derivadas dos direitos fundamentais.

Nas palavras de Llorente (2001, p. 18-19),

Quando a relação entre a proteção do direito e a imposição do dever de fazer ou não fazer é imediata, como ocorre, por exemplo, no caso de diversas normas penais, a origem constitucional de tal dever é facilmente discernível, mesmo que a licitude da norma possa ser questionada por outras razões (falta de proporcionalidade entre a finalidade e os meios, violação à igualdade, etc.). Quando, ao contrário, a relação entre a finalidade protetora dos direitos e dos deveres impostos pela norma não existe [...], ou apenas pode ser estabelecida através de uma longa série de mediações [...], a validade constitucional da norma pode ser questionada

\footnotetext{
${ }^{5}$ No original: "[...] es absurdo considerar deberes constitucionales los que existen como simple correlato de derechos fundamentales ajenos, o como limites internos de los próprios, o como consecuencia de la sujeción específica a órganos concretos del poder”. (LLORENTE, 2001, p. 17$18)$.
} 
também em razão do fim perseguido. $O$ enunciado constitucional de deveres serve para evitar esse tipo de questionamento, ou para facilitar a resposta à questão levantada, uma vez que habilita diretamente o legislador a impô-los coercitivamente [tradução livre] ${ }^{6}$.

Postos nesses termos, Llorente (2001, p. 14) demonstra que uma série de deveres aludidos na constituição não são deveres constitucionais, como, por exemplo, o dever dos pais assistirem os filhos, o de cumprir as decisões judiciais e os deveres recíprocos dos cônjuges.

Esse conceito restritivo de deveres constitucionais (ou "deveres em sentido estrito") é o que fundamenta a discussão do terceiro capítulo desse artigo, em que se avalia a compreensão de Llorente com a do GPEDDF em relação à possibilidade de aplicação de deveres constitucionais às relações privadas. Em outras palavras, a discussão da eficácia horizontal dos deveres constitucionais, que, pelo menos à primeira vista, é incompatível com a concepção de "imposições frente ao Estado".

Cabe ressaltar, ainda, que, apesar de serem majoritamente denominados como deveres constitucionais pela jurisprudência e literatura especializada, a Constituição Espanhola adota o termo deveres fundamentais, o que, segundo Llorente, pode ser atribuído à influência de Constituição de Weimar (LLORENTE, 2001, p. 12). Tendo isso em vista, trata-se de uma expressão inovadora escolhida pelo constituinte espanhol de 1978 para compor o Título I da Constituição. Apesar de existir, já na Constituição Espanhola de 1931, referência a deveres, apenas na Constituição em vigor há deveres qualificados como fundamentais, paralelamente

\footnotetext{
${ }^{6}$ No original: "Cuando la relación entre la protección del derecho y la imposición del deber de hacer o no hacer es immediata, como sucede, por ejemplo, en el caso de muchas normas penales, el origen constitucional de tal deber es fácilmente discernible, aunque la licitud de la norma pueda ser cuestionada por otras razones (falta de proporción entre el fin y los medios, infracción de la igualdad, etc.). Cuando, por el contrario, la relación entre la finalidad protectora de los derechos y los deberes impuestos por la norma no existe [...], o sólo puede ser establecida a través de una larga serie de mediaciones [...], la validez constitucional de la norma puede ser cuestionada también en razón del fin perseguido. El enunciado constitucional de deberes sirve para evitar esta puesta cuestión, o para facilitar la respuesta a la cuestión planteada, en cuanto que habilita directamente al legislador para imponerlos coactivamente" (LLORENTE, 2001, p. 18-19).
} 
aos direitos.

Outra questão é o fato de Llorente considerar que "deveres constitucionais" e “deveres fundamentais” não são sinônimos. Na verdade, para o autor, este último representa um subgrupo dentro do primeiro. Para fundamentar essa posição, Llorente considera peculiaridades da estrutura do texto constitucional espanhol, que podem ser resumidas da seguinte forma:

Quadro 1. Constituição Espanhola de 1978.

\begin{tabular}{|c|c|c|}
\hline \multicolumn{3}{|c|}{ Constituição Espanhola de 1978} \\
\hline Título preliminar & Capítulo & Seção \\
\hline \multicolumn{3}{|l|}{$\begin{array}{l}\text { Título I. Dos direitos e } \\
\text { deveres fundamentais }\end{array}$} \\
\hline & $\begin{array}{lrr}\text { Capítulo } & \text { I. } & \text { Dos } \\
\text { espanhóis } & \text { e } & \text { dos } \\
\text { estrangeiros } & & \\
\end{array}$ & \\
\hline & $\begin{array}{l}\text { Capítulo II. Direitos e } \\
\text { liberalidades }\end{array}$ & \\
\hline & & $\begin{array}{l}\mathbf{1}^{\text {a }} \text { Seção. Dos direitos e das } \\
\text { liberdades públicas }\end{array}$ \\
\hline & & $\begin{array}{l}2^{\mathbf{o}} \text { Seção. Dos direitos e } \\
\text { deveres dos cidadãos }\end{array}$ \\
\hline & $\begin{array}{l}\text { Capítulo III. Dos } \\
\text { princípios orientadores } \\
\text { da política social e } \\
\text { econômica }\end{array}$ & \\
\hline & $\begin{array}{l}\text { Capítulo IV. Das } \\
\text { garantias das liberdades } \\
\text { e direitos fundamentais }\end{array}$ & \\
\hline & $\begin{array}{l}\text { Capítulo } \quad \text { V. Da } \\
\text { suspensão dos direitos e } \\
\text { liberdades }\end{array}$ & \\
\hline Título II. Da Coroa & & \\
\hline $\begin{array}{l}\text { Título III. Das Cortes } \\
\text { Gerais }\end{array}$ & & \\
\hline & $\begin{array}{lll}\text { Capítulo } & \text { I. } & \text { Das } \\
\text { Câmaras } & & \\
\end{array}$ & \\
\hline & Capítulo & \\
\hline
\end{tabular}




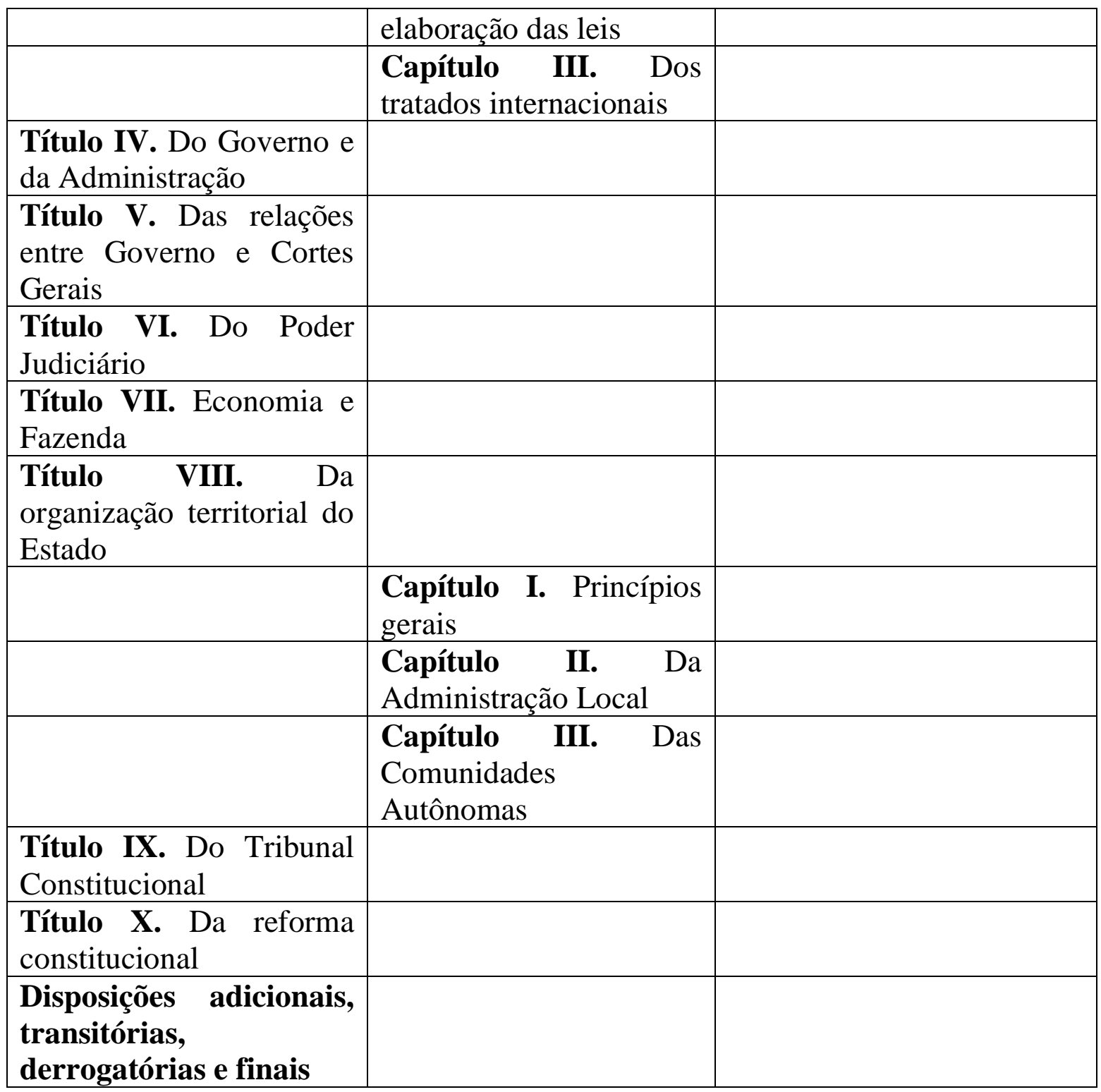

Fonte: o autor, 2020.

$\mathrm{O}$ art. 149, 1, $1^{\circ}$ da Constituição Espanhola determina que o Estado tem competência exclusiva para regulamentar aquelas condições básicas que garantem a igualdade de todos os espanhóis no cumprimento dos "deveres constitucionais". O art. 94, 1, c, determina que tratados internacionais que versarem sobre os "deveres fundamentais" estabelecidos no Título I demandarão prévia autorização do Legislativo. O art. 86, 1, ao atribuir competência para o Poder Executivo editar Decreto-Lei em caso de urgência ou necessidade extraordinária, limita, ao mesmo 
tempo, esse poder aos deveres regulamentados no Título I.

Conforme se observa, há uma série de disposições que exigem que deveres fundamentais expressos no Título I sejam, necessariamente, regulados por espécies normativas que contam com a participação do Poder Legislativo. Apesar disso, não é apenas no Título I onde se encontram os deveres constitucionais, na forma conceituada por Llorente. Por exemplo, o dever de conhecer o Castelhano está disposto no art. 3, 1, da Constituição Espanhola, que não pertence ao Título I, mas ao Título Preliminar do texto constitucional.

Por conta disso, Llorente (2001, p. 23) defende que os deveres constitucionais dispostos no Título I da Constituição Espanhola, por pertencerem ao subgrupo dos deveres fundamentais, demandam lei em sentido formal para sua regulamentação, enquanto os demais deveres constitucionais poderiam ser regulamentados por Decreto-Lei ou por tratados internacionais sem ratificação pelo Poder Legislativo.

O próprio Llorente ressalta, no entanto, que essa distinção é primordialmente teórica e dificilmente poderá ser aplicada na prática. Isso porque, em regra, a regulamentação dos deveres constitucionais estranhos ao Título I afetam direitos fundamentais, o que faria permanecer a exigência de lei em sentido formal para sua regulamentação (LLORENTE, 2001, p. 24).

Assim, pode-se resumir que a primeira parte do artigo de Llorente estabelece que nem todo dever aludido na Constituição Espanhola é um dever constitucional (já que esses últimos são apenas aqueles autônomos em relação à direitos fundamentais e ao exercício de competência de órgãos específicos) e que, dentre os deveres constitucionais há os deveres fundamentais, dispostos no Titulo I do texto constitucional, que se diferenciam por demandar lei em sentido formal para sua regulamentação.

Em contrapartida, a experiência do Grupo de Pesquisa "Estado, Democracia e Direitos Fundamentais", do Programa de Pós-Graduação Stricto Sensu da 
Faculdade de Direito de Vitória (FDV), desenvolveu o seguinte conceito de deveres fundamentais:

\begin{abstract}
Dever fundamental é uma categoria jurídico-constitucional, fundada na solidariedade, que impõe condutas proporcionais àqueles submetidos a uma determinada ordem democrática, passíveis ou não de sanção, com a finalidade de promoção de direitos fundamentais (GONÇALVES; FABRIZ, 2013, p. 92).
\end{abstract}

O conceito de deveres fundamentais elaborado pelo GPEDDF assemelha-se ao conceito de Llorente para "deveres aludidos na Constituição", posto que abarca tanto deveres fundamentais autônomos em relação a direitos fundamentais quanto deveres correlatos a estes.

Para o Grupo de Pesquisa, o tratamento dos deveres fundamentais enquanto uma categoria jurídico-constitucional não significa uma autonomia jurídica, posto que os deveres fundamentais sempre teriam como finalidade última a proteção de direitos fundamentais. Tratar-se-ia, na verdade, de autonomia teórica, podendo-se utilizar dessa categoria para fins didáticos de estudo e pesquisa (GONÇALVES; FABRIZ, 2013, p. 92).

No entendimento dos integrantes do Grupo de Pesquisa:

[...] colocar o dever fundamental como uma categoria jurídicoconstitucional o leva a uma autonomia teórica relativamente aos direitos fundamentais, e isso deve sempre ser levado em consideração quando argumentar-se acerca de um dever fundamental específico (GONÇALVES; FABRIZ, 2013, p. 92).

Ainda assim, quando se observa a argumentação de Llorente sobre a função dos deveres fundamentais em habilitar o legislador para instituir deveres que poderiam ser questionados em relação a sua finalidade de promoção a direitos fundamentais, conforme explicado, conclui-se que, também para o autor espanhol, a relação de autonomia dos deveres constitucionais em sentido estrito não é absoluta.

Também a característica dos deveres fundamentais enquanto decorrentes de 
"status geral de sujeição ao poder", dada por Llorente, assemelha-se ao conceito do Grupo de Pesquisa no que tange aos destinatários enquanto "àqueles submetidos a uma determinada ordem democrática".

Por outro lado, o conceito do Grupo de Pesquisa não distingue as figuras de "deveres constitucionais", "deveres fundamentais" e "deveres aludidos na Constituição", que foram desenvolvidos por Llorente enquanto fruto da tradição constitucional espanhola e o texto constitucional daquele país.

Nesse sentido, poder-se-ia, à título de exercício de raciocínio, refletir se a crítica de Llorente em relação à insuficiência da identificação dos deveres constitucionais a todo enunciado que contenha expressões imperativas (como "dever", "deve", etc.) também se aplicaria ao conceito mais alargado do Grupo de Pesquisa.

A resposta é negativa. Isso porque, o conceito do Grupo de Pesquisa prescinde de expressões no direito positivo e fundamenta-se na solidariedade, que, por sua vez, reconhece o caráter gregário das sociedades humanas para haja contribuições suficientes para o atingimento dos objetivos comuns (PEDRA, 2015, p. 1137). Observa-se, nesse sentido, um critério material não positivista para a identificação dos deveres fundamentais.

Ao basear a ideia de deveres fundamentais na solidariedade, o Grupo de Pesquisa também adiciona a característica da proporcionalidade da conduta exigida a título de dever fundamental. Isso contrabalanceia a dimensão valorativa da solidariedade com um aspecto técnico para diminuir subjetividade e arbitrariedade. Nas palavras do Grupo de Pesquisa:

A proporção na conduta imposta é importante para manter o respeito aos valores de um Estado Democrático de Direito, e a escolha de palavras [...] foi feita devido à delimitação jurídica do trabalho, uma vez que a proporcionalidade é uma definição já existente na área e, portanto, carrega já consigo o conteúdo pretendido (GONÇALVES; FABRIZ, 2013, p. 92). 
O conceito do Grupo de Pesquisa abre espaço para se afirmar, inclusive, a existência de deveres fundamentais autoaplicáveis, o que é objeto de análise do quarto capítulo deste artigo.

Apresentadas as características que compõem os conceitos de deveres aludidos na constituição, deveres constitucionais e deveres fundamentais para Llorente, e comparando-as com o conceito de deveres fundamentais na produção bibliográfica do Grupo de Pesquisa Estado, Democracia e Direitos Fundamentais, é possível adentrar na análise dos dois outros tópicos selecionados para estudo: a eficácia horizontal e a autoaplicabilidade dos deveres fundamentais. Antes disso, entretanto, será sistematizada a produção bibliográfica do GPEDDF.

\section{SiSTEMATIZAÇÃO DA PRODUÇÃO ACADÊMICA DO GRUPO DE PESQUISA ESTADO, DEMOCRACIA E DIREITOS FUNDAMENTAIS}

Na forma já mencionada, a produção acadêmica do Grupo de Pesquisa Estado, Democracia e Direitos Fundamentais pode ser dividida em três categorias: (i) a produção relativa à teoria geral dos deveres fundamentais; (ii) à deveres fundamentais em espécies; (iii) ou a abordagens comparativas entre o Brasil e outras experiências constitucionais.

Formam o banco de dados do $\mathrm{GPEDDF}^{7} 72$ arquivos digitais, que podem ser depurados $^{8}$ em artigos 69 artigos sobre deveres fundamentais. Para os fins de sistematização da produção bibliográfica do Grupo de Pesquisa, foram separados $67^{9}$ artigos, excluindo-se um que foi publicado em língua francesa (PEDRA, 2014)

<https://www.dropbox.com/sh/bo5c3whefh8ux7f/AADWjtW2dzYUXTj5ucOzWwaCa/Textos\%20 produzidos\%20no\%20GP?dl=0\&lst=\&subfolder_nav_tracking=1>. Acesso em: 23 nov. 2018.

${ }^{8}$ Nesse caso, os 69 artigos selecionados no processo depuração decorrem da exclusão de arquivos repetidos ou de outra natureza.

9 Compõe a amostra analisada os seguintes artigos: Siqueira (2010, 2011, 2016); Homem de Siqueira (2009, 2011, 2016); FARO (2012, 2012b, 2012c, 2012d, 2012e, 2013, 2014); Faro e 
e outro que trata apenas da justificativa de projetos de pesquisa em deveres fundamentais (SIQUEIRA; FABRIZ, 2011).

O Gráfico 1 mostra como a publicação da produção bibliográfica do GPEDDF está distribuída no tempo:

\section{Gráfico 1 - Artigos Publicados em Relação ao Ano de Publicação - 2009/2018}

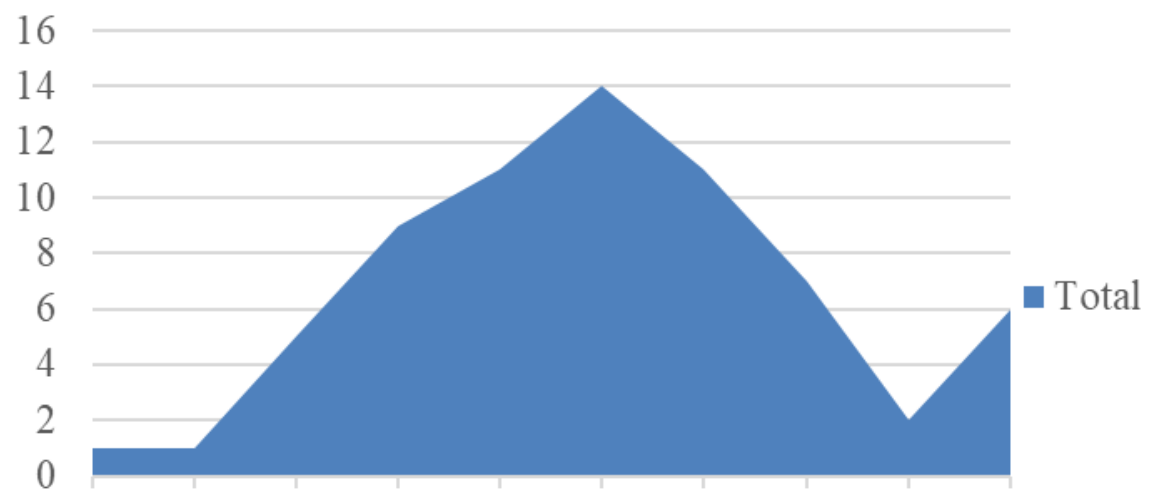

2009201020112012201320142015201620172018

Fonte: O autor, 2020.

A partir dele, observa-se que a produção do GPEDDF já abrange o período entre 2009 e 2018, cujo pico de publicação ocorreu em 2014, quando foram publicados catorze artigos.

Além disso, é possível analisar a amostra de artigos publicados conforme as categorias anteriormente apresentadas, que pode ser transposta para o Gráfico 2:

Fabriz (2012); Abikair Filho e Fabriz (2013, 2014); Gonçalves e Fabriz (2013, 2013b); Vieira e Pedra (2013); Marques e Fabriz (2013); Duque e Pedra (2013, 2015); Tavares e Pedra (2014, 2015), Pedra (2013, 2014, 2015, 2015b, 2016); Abreu (2013); Abreu e Fabriz (2014); Colnago e Pedra (2014, 2015, 2015b, 2016); Colnago (2014, 2014b); Fabriz e Obregón (2014); Lacerda e Faro (2014, 2014b); Fonseca e Leite (2015); Simões e Fabriz (2015) Obregón e Fabriz (2015); Silva e Fabriz (2015); Silva e Pedra (2016, 2017); Fabriz e Silva (2016, 2018); Gonçalves (2018); Berger e Pedra (2018); Costa e Fabriz (2018); Pedra e Groberio (2018); Laranja e Fabriz (2018); Bernardo Segundo e Pedra (2011); Vello e Pedra (2011); Buarque e Pedra (2016); Guedes e Fabriz (2017); Silva (2012); Silva, Gonçalves e Fabriz (2014); Gonçalves e Pedra (2011); Galante e Pedra (2014); Pedra e Freitas (2015); Pedra e Pedra (2012); Machado e Pedra (2012, 2013, 2014). 
Gráfico 2 - Artigos Publicados por Categoria e Subcategoria - 2009/2018.

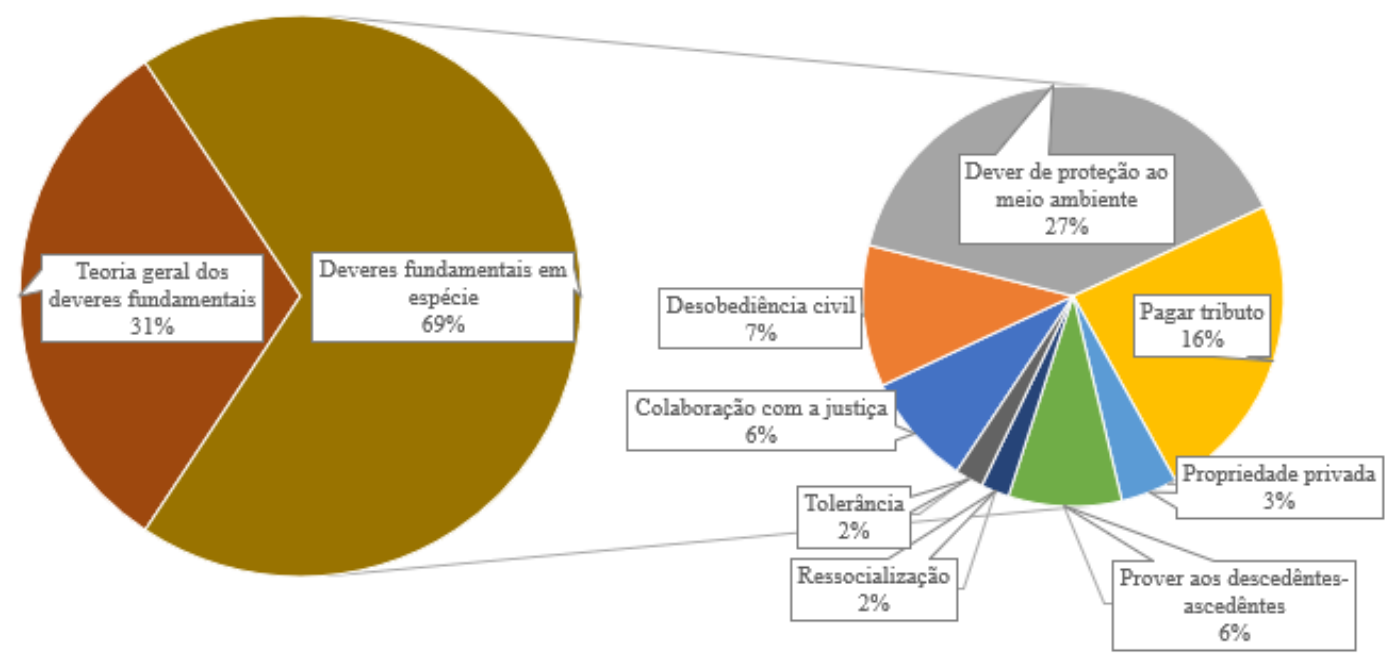

Fonte: O autor, 2020.

Do ponto de vista das categoriais principais, observa-se que $31 \%$ dos artigos publicados entre o período de 2009 e 2018 versam sobre aspectos de teoria geral dos deveres fundamentais, dos quais se pode incluir questões de eficácia, sanção, taxonomia e conceito. Em contrapartida, 69\% da produção trata de deveres fundamentais em espécie, de forma que os aspectos gerais são utilizados para gerar inferências em situações específicas. Destaca-se, também, que não foram identificadas produções bibliográficas que pudessem ser classificadas como pertencente à terceira categoria, qual seja a pesquisa comparativa entre deveres fundamentais no ordenamento jurídico brasileiro com aqueles presentes em legislação estrangeira.

Ressalva-se, entretanto, que existe na amostra pesquisas que fazem remissão a deveres fundamentais presentes em outros ordenamentos jurídicos. Apesar isso, esses artigos não foram enquadrados em uma categoria própria, posto que o tema não representa a discussão principal do texto, mas apenas elementos ilustrativos, exemplificativos ou secundários. Por exemplo, no texto "Deveres Fundamentais e 
sua Previsão em Tratados Internacionais Firmados pelo Brasil” (PEDRA, 2015b) trechos de Constituições estrangeiras são utilizadas para justificar o caráter constitucional dessas normas.

Não é em outro sentido que, em diversos textos, apareceram questões de teoria geral junto com aspectos de deveres fundamentais em espécies. Assim sendo, a classificação busca apenas identificar qual dimensão do problema de pesquisa e resultados alcançados é enfatizada.

Quando são observados, ainda no Gráfico 2, os dados relativos aos artigos sobre deveres fundamentais em espécie, observa-se que os três principais temas produzidos são meio ambiente (27\%), pagar tributos (16\%) e desobediência civil (7\%), respectivamente.

Um dos fatores que explica a quantidade de publicação sobre o dever fundamentação de proteção ao meio ambiente é o fato de ser utilizado um conceito alargado, abarcando não apenas o meio ambiente natural, mas também desenvolvendo pesquisa sobre o meio ambiente digital, laboral e cultural.

Quando as informações da Gráfico 1 e Gráfico 2 são cruzadas, torna-se possível avaliar a produção bibliográfica no GPEDDF por tempo e categoria, na forma do Gráfico 3: 
Gráfico 3 - Artigos Publicados por Categoria e Subcategoria e por ano de publicação 2009/2018.

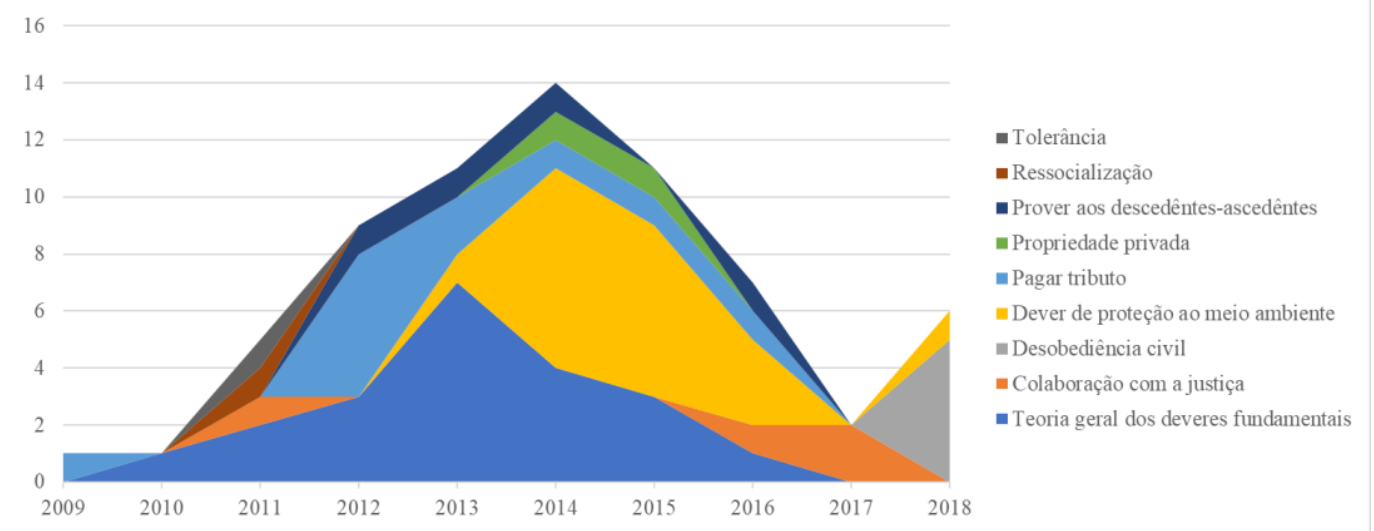

Fonte: O autor, 2020.

Observa-se, nesse sentido, que o tema "teoria geral dos deveres fundamentais" acompanha a maior parte do período de pesquisa do GPEDDF, com exceção apenas de 2017 e 2018. Lembra-se, ainda, que a amostra objeto de análise deste artigo não comtempla todo o ano de 2018, fazendo com que esse dado ainda possa sofrer alteração.

É possível inferir, também, que o tema dos deveres fundamentais em espécie passa por ciclos. O primeiro tema que demonstrou alguma concentração foi o de pagar tributos, com alguma presença em 2009 e mais concentrado em 2012. Esse fenômeno pode ser explicado pelo fato de se tratar de um dos deveres fundamentais em espécies mais estudos pela academia brasileira e estrangeira, o que permitiria um maior diálogo para o início das produções do GPEDDF.

As publicações sobre proteção ao meio ambiente se concentraram entre 2013 e 2016, enquanto a colaboração da justiça entre os anos de 2016 e 2016. Em relação ao último, pode-se inferir que promulgação do Código de Processo Civil em 2015 justifica essa concentração nos anos seguintes. 
Essa sistematização, além de permitir uma visão geral da produção bibliográfica do GPEDDF, identificando suas características, demonstra uma atuação de estudo e pesquisa consistente do tema, justificando o fato de ser uma referência no Brasil sobre deveres fundamentais.

Isto posto, pode-se avançar e tratar de dois tópicos selecionados para uma comparação qualitativa entre as ideias do GPEDDF e Llorente, que são aquelas questões referentes à eficácia horizontal dos deveres fundamentais, que é analisado no terceiro capítulo, e referentes à existência de deveres fundamentais autoaplicáveis, discutido no quarto capítulo.

\section{DEVERES CONSTITUICIONAIS EM SENTIDO ESTRITO POSSUEM EFICÁCIA HORIZONTAL?}

Conforme apresentou-se no primeiro capítulo deste artigo, a obra de Llorente sugere que "deveres em sentido estrito" são apenas aqueles que existem frente ao Estado, o que exclui, por conseguinte, aqueles deveres constitucionalmente instituídos, mas voltados para as relações entre particulares.

O estudo dos direitos fundamentais, entretanto, está mais avançado. Originariamente, os direitos fundamentais também foram vistos apenas como prerrogativas dos indivíduos frente ao Estado. É o que explica, por exemplo, Perez Luño (2004, p. 29), ao dizer que

O termo 'direitos fundamentais', droits fondamentaux, aparece na França por volta do ano de 1770 no marco do movimento político e cultural que conduziu à Declaração dos Direitos do Homem e do Cidadão, de 1789. A expressão alcançou logo especial relevo na Alemanha, onde, sob a denominação de Grundrechte, articulou-se de modo especial através da Constituição de Weimar de 1919, o sistema de relações entre o indivíduo e o Estado, enquanto fundamento de todo o ordenamento jurídico-político 
[tradução livre] ${ }^{10}$.

Essa abordagem, de matriz majoritariamente liberal, fundamentou a perspectiva de que os direitos fundamentais são normas com eficácia vertical, ou seja, aplicam-se na relação entre soberano e subordinado, Estado e indivíduo.

A perspectiva de Llorente (2001, p. 19) transporta essa concepção para a questão dos deveres fundamentais:

Os deveres recíprocos dos cônjuges a que alude o artigo 32 (30) não são, como é claro, deveres que a Constituição pretende impor a todos [...]. Tão pouco são deveres de todos frente a todos, ou frente ao Estado, aqueles que os pais têm de prestar assistência aos seus filhos [...] [tradução livre] ${ }^{11}$.

A visão de eficácia meramente vertical, entretanto, tem sido paulatinamente superada pela compreensão de que direitos fundamentais possuem eficácia erga omnes. Assim, sem negar a eficácia vertical dessas normas, reconhece-se, também, a sua aplicabilidade nas relações entre particulares, denominada eficácia horizontal. A partir dessa perspectiva mais moderna dos direitos fundamentais, Campos (1989, p. 24) considera que os esses direitos têm a característica da "ambivalência".

No campo dos direitos fundamentais, a razão para se defender uma ampla aplicação dessas normas é a importância que elas possuírem no asseguramento da dignidade humana e compreensão de que existem outros atores sociais que, além do Estado, ameaçam cotidianamente essa dignidade.

\footnotetext{
${ }^{10}$ No original: "El término $<<$ derechos fundamentales $>>$, droits fondamentaux, aparece en Francia hacia el año 1770 en el marco del movimiento político y cultural que condujo a la Declaración de los Derechos del Hombre y del Ciudadano, de 1789. La expresión há alcanzado luego especial relieve em Alemania, donde bajo la denominación de los Grundrechte se ha articulado, de modo especial tras la Constituición de Weimar de 1919, el sistema de relaciones entre el individuo y el Estado, en cuanto fundamento de todo el orden jurídico-político".

${ }^{11}$ No original: "Los deberes recíprocos de los cónyuges a los que alude el artículo 32 (30) no son, com es claro, deberes que la Constituición pretenda imponer a todos [...]. Tampouco son deberes de todos frente a todos, o frente al Estado, los que los padres tienen de prestar asistencia a los hijos $[\ldots] "$.
} 
Alcalá (2003, p. 74-75), ao tratar do assunto, considera que:

Eficácia vertical e horizontal dos direitos fundamentais outorga segurança jurídica a tais direitos; impede o desenvolvimento de uma ética dupla na sociedade, uma nas relações com o Estado e outra para as relações entre os particulares; tudo isso considerando que muitas das principais ameaças aos direitos não provêm apenas do Estado, mas também, e principalmente, dos poderes econômicos e sociais fáticos da própria sociedade civil [tradução livre] ${ }^{12}$.

Tendo em vista essa ideia de que não é apenas o Estado que viola direitos fundamentais e, portanto, não apenas a ele cabe àquelas condutas, positivas ou negativas, que visam a permitir e coexistência humana (solidariedade) em sociedade, o Grupo de Pesquisa da FDV tem buscado identificar e analisar deveres fundamentais que possuem eficácia horizontal.

É o caso, por exemplo, do artigo "Os deveres fundamentais e a solidariedade nas relações privadas" (DUQUE; PEDRA, 2013, p. 158), em que se defende que uma fundamentação da eficácia horizontal dos deveres fundamentais a partir da concepção de que determinados ônus estatais são repassados para os particulares.

Um típico exemplo dessa realidade é a regra interpretativa do direito de família brasileiro, em que a tutela jurisdicional deve pautar-se no melhor interesse da criança, mesmo que em sacrifício do interesse dos pais, posto que a estes últimos é repassado o dever de educação e amparo. Isso também pode ser observado pelo comportamento jurisprudencial em causas envolvendo os setores de bancos, seguros, educação e moradia, em que é repassado para agentes privados o dever de efetivar direitos fundamentais e, portanto, abster-se de pactuar condições abusivas ou desproporcionais em relação aos bens ou serviços prestados.

\footnotetext{
12 No original: "Esta eficacia vertical y horizontal de los derechos fundamentales otorga seguridad jurídica de tales derechos; impide el desarrollo de una doble ética en la sociedad, una en las relaciones con el Estado y otra para las relaciones entre particulares; todo ello considerando que muchas de las principales amenazas a los derechos no provienen sólo del Estado, sino también, y principalmente, de los poderes económicos y sociales fácticos de la propia sociedad civil”.
} 
Observa-se, nesse sentido, que tanto nas relações de consumo quanto nas relações entre a Administração Pública e o administrado, há a imposição de responsabilidade objetiva no relacionamento com consumidores e cidadãos, mais um elemento que demonstra a busca por se harmonizar regras de condutas que permitam evitar, no termo apresentado por Alcalá (2003, p. 74-75), uma "ética dupla”, tanto na esfera dos direitos fundamentais quanto na dos deveres.

Não se pode concordar, nesse sentido, não haver deveres fundamentais orientando as relações entre pais e filhos ou entre o mercado de consumo e os consumidores, posto que a tutela desses direitos não é realizada conforme simples regras de direito privado. Na verdade, valores coletivos interferem na interpretação e aplicação do direito quando se está diante desses casos, bem como a solidariedade fundamenta a imposição de condutas que permitem a submissão dos indivíduos à eficácia horizontal de deveres fundamentais.

\section{EXISTEM DEVERES CONSTITUCIONAIS AUTOAPLICÁVEIS?}

Uma vez observada a distinção entre a perspectiva de Llorente e do Grupo de Pesquisa da FDV em relação à existência de eficácia horizontal para os deveres fundamentais, cabe analisar um segundo tópico: a possibilidade de deveres constitucionais autoaplicáveis.

Llorente defende que a exigência dos deveres constitucionais depende, por seu turno, de uma regulamentação infraconstitucional para que possa ser eficaz. Trata-se, nesse sentido, daquela corrente de pensamento que acredita que o destinatário imediato das normas de deveres fundamentais sempre será o Estado ${ }^{13}$ (LLORENTE, 2001, p. 21).

No tópico anterior, buscou-se relativizar essa compreensão a partir da ideia de eficácia horizontal para determinados direitos, pautando-se, sobretudo, na

${ }^{13}$ No mesmo sentido entende José Casalta Nabais. Vide NABAIS (2012). 
compreensão que determinadas atribuições estatais necessárias à coexistência são, por vezes, delegadas à particulares, sendo necessário, nesse sentido, o cumprimento de deveres fundamentais para sua correta aplicação.

Esse posicionamento fica evidente quando o autor trata do dever de conservar o meio ambiente adequado para o desenvolvimento das pessoas, conforme disposto no artigo 45 da Constituição Espanhola. Nas palavras de Llorente (2001, p. 32):

O meio ambiente cujo gozo consagra a Constituição como direito e cuja conservação impõe-se como um dever, é o "adequado para o desenvolvimento da pessoa", e como é óbvio que nem para um, nem para outro, pode-se utilizar como critério de "adequado" a opinião pessoal do titular do direito ou do obrigado ao dever, a definição deste requer inescusavelmente a intervenção do poder, e o dever de conservar o meio ambiente se traduz, na prática, no de obedecer o direito objetivo que o protege $^{14}$ [tradução livre].

Essa posição, em que pese buscar prestigiar o princípio da legalidade, tem alcançado um desenvolvimento diferente na jurisprudência brasileira e internacional, sendo objeto de estudo do artigo "A Eficácia dos Deveres Fundamentais" (TAVARES; PEDRA, 2014), elaborado junto ao Grupo de Pesquisa da FDV.

No texto, também se faz a ressalva a impossibilidade de uma simples importação da noção de auto-aplicabilidade dos direitos para a questão dos deveres, defendendo-se, que, muitas vezes, será necessário a utilização da lei para a criação de novas obrigações. Entretanto, não se nega a impossibilidade de deveres autoaplicáveis.

${ }^{14}$ No original: "El medio ambiente cuyo goce consagra la Constitución como derecho y cuya conservación impone como deber, es el $<<$ adequado para el desarrollo de la persona $>>$, y como es obvio que ni para lo uno ni para lo otro puede utilizarse como criterio de <<lo adecuado >> la opinión personal del titular del derecho o del obligado por el deber, la definición de este requiere inexcusablemente la intervención del poder, y el deber de conservar el medio ambiente se traduce en la prática en el de obedecer el derecho objetivo que lo protege" (LLORENTE, 2001, p. 32). 
A possibilidade de auto-aplicabilidade dos deveres fundamentais está na investigação da natureza do comportamento exigido. Para aqueles comportamentos que necessitam de forma própria para se assegurar a proporcionalidade e isonomia, é necessária lei que o estabeleça. Entretanto, alguns comportamentos não necessitam dessa aferição prévia.

Baseados nessa ideia, Tavares e Pedra (2014, p. 17) sustentam que:

Algumas espécies de deveres fundamentais possuem exigência expressa de lei para sua exigência (dever de contribuir), de modo que só podem ser exigidas, vale dizer, têm eficácia jurídica condicionada à intervenção do legislador infraconstitucional. Outras espécies de deveres para os quais o legislador constituinte não fez idêntica exigência, serão aplicáveis (têm eficácia jurídica) independentemente da intervenção do legislador infraconstitucional, sempre em observância aos direitos fundamentais, especialmente de defesa.

A partir dos exemplos dados, observa-se que o dever de contribuir com as despesas públicas por meio do pagamento de tributos é um caso de comportamento que exige lei (inclusive expressamente disposto no art. 150, I, da Constituição Federal), posto que o quantum devido por cada cidadão precisa ser previamente aferido, sob o risco de desvirtuar a capacidade contributiva, criando obrigações desproporcionais ou não igualitárias.

Ressalta-se, apenas, que no GPEDDF existe uma discussão sobre a possibilidade do Poder Judiciário poder exercer atividade legislativa stricto sensu nos casos em que a ausência de regulamentação do tributo poder ser configurada como uma inconstitucionalidade por omissão. Essa ideia é defendida no texto "Dever fundamental de pagar tributos, omissão legislativa inconstitucional e deslocamento provisório da competência legislativa" (PEDRA; PEDRA, 2012). Apesar disso, parece unanimidade a necessidade de um instrumento infraconstitucional que densifique o dever fundamental de pagar tributo.

Em sentido similar, o dever fundamental de preservar o meio ambiente ecologicamente equilibrado, disposto no art. 225 da Constituição Federal Brasil, 
estabelece que o Estado pode exigir que os cidadãos realizem estudo prévio de impacto ambiental para a instalação de empreendimentos econômicos, mas apenas na forma da lei (art. $225, \S 1^{\circ}, \mathrm{IV}$ ). Isso também decorre do próprio dever, posto que a livre-iniciativa e a livre concorrência poderiam ser afetadas caso existissem regras desproporcionais ou não igualitárias para concessão de licenças ambientais.

Por outro lado, parte do dever fundamental de proteção ao meio ambiente pode ser considerado autoaplicável. Trata-se do dever de reparação pelo dano ambiental causado. Há situações, como desmatamento ou despejo de resíduos, em que é possível individualizar o nexo de causalidade e quantificar o dano gerado. Nos casos em que isso for possível, não há necessidade de uma lei infraconstitucional que simplesmente repita o texto constitucional para se imputar o dever de reparar.

A lei poderia, por óbvio, regulamentar situações de responsabilidade solidária ou subsidiária, relações de sucessão, etc. No mesmo sentido, a lei poderia estabelecer as sanções administrativas ou penais. Tudo isso depende de prévia análise de proporcionalidade e isonomia e só pode ser feito pela regulamentação infraconstitucional. Entretanto, essas ponderações não eliminam a possibilidade de auto-aplicabilidade do dever fundamental de reparar o dano ambiental por aquele que o causou, quando atendidos os requisitos já mencionados.

Nesse sentido, o ordenamento constitucional brasileiro parece corroborar com essa hipótese, ao dispor, no art. $225, \S 3^{\circ}$, que "As condutas e atividades consideradas lesivas ao meio ambiente sujeitarão os infratores, pessoas físicas ou jurídicas, a sanções penais e administrativas, independentemente da obrigação de reparar os danos causados".

Qualquer legislação infraconstitucional no Brasil que se predispor a "regulamentar" o dever de reparar o dano ambiental causado não faria nada mais que simplesmente repetir o dispositivo constitucional, demonstrando, mais uma vez, que existem exemplos de deveres fundamentais auto-aplicáveis.

A mesma conclusão é apresentada no texto "A importância dos deveres 
humanos na efetivação de direitos" (PEDRA, 2013), cujo exemplo utilizado naquela oportunidade foi o reconhecimento do regime jurídico das uniões estáveis às uniões homoafetivas, jurisprudência que não apenas densificou direitos, mas também deveres fundamentais conjugais.

Por isso posto, observa-se que autoaplicabilidade dos deveres fundamentais pode inferida de situações práticas do constitucionalismo brasileiro e surge como uma necessidade da própria necessidade de efetividade de direitos fundamentais.

\section{CONCLUSÃO}

A partir da análise do texto "Los deberes constitucionales", de autoria de Francisco Rubio Llorente, foi possível comparar o desenvolvimento das ideias sobre deveres fundamentais (constitucionais) na Espanha e compará-lo com a produção acadêmica do Grupo de Pesquisa "Estado, Democracia e Direitos Fundamentais" do Programa de Pós-Graduação Stricto Sensu da Faculdade de Direito de Vitória (FDV).

Com esse objetivo, pode-se compreender que o conceito de deveres constitucionais em sentido estrito, que seria a ideia mais próxima de "deveres fundamentais" produzido pelo GPEDDF da FDV, possui semelhanças com a produção capixaba quando se observa a busca por criar uma categoria autônoma de deveres necessários à coexistência em um Estado Democrático de Direito.

Por outro lado, também foi possível concluir que existe uma diferença essencial no fundamento das duas ideias. Para o autor espanhol, uma categoria autônoma de deveres constitucionalmente instituídos tem como fundamento o “status geral de sujeição ao Estado", enquanto para o Grupo de Pesquisa brasileiro essa categoria fundamenta-se na solidariedade.

Baseada nessas ideias, o GPEDDF construiu um sólido histórico em pesquisa e estudo em deveres fundamentais. Foi possível sistematizar um amostra de artigos 
que cobrem o período entre 2009 e 2018, a partir do que identificou-se uma produção voltada tanto para aspectos da teoria geral dos deveres fundamentais quanto para deveres fundamentais em espécie, dos quais se destacam, por sua vez, o dever fundamental de proteger o meio ambiente (natural, laboral, digital e cultural), o dever de pagar tributos e o tema da desobediência civil.

Ao fundamentar seu conceito na solidariedade, o Grupo de Pesquisa da FDV também permite que se vá além da tradicional ideia de eficácia vertical dos deveres fundamentais, sustentando-se, além disso, uma eficácia horizontal. Isso permite aproveitar parte dos mais recentes desdobramentos da teoria geral dos direitos fundamentais e aplicá-los na questão dos deveres.

Outra contribuição dada pela investigação proposta, foi na reflexão acerca da auto-aplicabilidade dos deveres fundamentais. Como resultado, vislumbrou-se, que, em regra, ainda há necessidade de regulamentação posterior para a exigência de deveres fundamentais para se resguardar o princípio da legalidade, principalmente no que tange às sanções.

Entretanto, a discussão sobre os deveres decorrentes dos direitos e deveres difusos, em especial o dever de contribuir para um meio ambiente ecologicamente equilibrado, permitiu a reflexão sobre a auto-aplicabilidade do dever de reparação quando os critérios de proporcionalidade e equidade podem ser aferidos do próprio dano gerado.

Em geral, a comparação da produção bibliográfica do GPEDDF e a obra de Llorente permitiu inferir que o Grupo de Pesquisa brasileiro possui uma visão mais progressista, em um esforço de aproximar o desenvolvimento dos deveres fundamentais à sistemática dos direitos, o que, por sua vez, reforça a concepção de complementariedade que esses dois institutos jurídicos possuem na construção do Estado Democrático de Direito.

\section{REFERÊNCIAS}


ABIKAIR FILHO, Jorge; FABRIZ, Daury César. A teoria geral da prestação do dever fundamental, sob a ótica de Lévinas. Derecho y Cambio Social, Lima, a. 10, n. 31, 2013.

ABIKAIR FILHO, Jorge; FABRIZ, Daury César. Dever fundamental, solidariedade e comunitarismo. Derecho y Cambio Social, Lima, a. 11, n. 35, 2014.

ABREU, Ivy de Souza. O dever fundamental de recuperação, manutenção e proteção das matas ciliares e das nascentes: uma análise do Código Florestal brasileiro à luz do princípio da proibição do retrocesso. Espaço Jurídico Jornal of Law, Chapecó, v. 14, n. 2, p. 583-596, jul./dez. 2013.

ABREU, Ivy de Souza; FABRIZ, Daury César. O dever fundamental de proteção do meio ambiente e seu fundamento na solidariedade: uma análise à luz do holismo ambiental. Derecho y Cambio Social, Lima, a. 10, n. 35, 2014.

ALCALÁ, Humberto Nogueira. Teoría y dogmática de los derechos fundamentales. México: Universidad Nacional Autónoma de México, 2003.

BERGER, Rosa Elana Krause; PEDRA, Adriano Sant'Ana. O dever fundamental de desobedecer diante de um governo corrupto e opressivo. Revista Brasileira de Estudos Políticos, Belo Horizonte, n. 116, p. 11-62, jan./jun. 2018.

BERNARDO SEGUNDO, Ronaldo Louzada; PEDRA, Adriano Sant'Ana. Limites ao dever de tolerância. In: BUSSINGER, Elda Coelho de Azevedo (Orgs.). Direitos fundamentais: pesquisas. p. 201-208. Curitiba: Editora CRV, 2011.

BRASIL. Constituição (1998). Constituição da República Federativa do Brasil. Brasília: Senado Federal; Centro Gráfico, 1988.

BUARQUE, Rodrigo Costa; PEDRA, Adriano Sant'Ana. A recusa das partes à audiência preliminar no novo código de processo civil: necessidade de motivação ante o dever fundamental de cooperação com a justiça. Revista Magister de Direito Civil e Processual Civil, n. 72, maio./jun., 2016.

CAMPOS, German J. Bidart. Teoría general de los derechos humanos. México: Universidad Nacional Autónoma de México, 1989.

CANOTILHO, José Joaquim Gomes. Direito constitucional e teoria da constituição. 7. ed. Coimbra: Almedina, 2004. 
COLNAGO, Cláudio de Oliveira Santos. Provedores de conexão e guarda de registros de acesso a aplicações de internet: o art. 14 do marco civil no contexto do dever fundamental de preservação do meio ambiente digital. In: LEITE, George Salomão; LEMOS, Ronaldo. (Coords.). Marco Civil da Internet. São Paulo: Atlas, 2014.

The right to be forgotten and the duty to implement oblivion: a challenge to both "old" and "new" media. In.: World Congress of Constitutional Law. Workshop 14: new challenges to the freedom of the media. Oslo, 2014b.

COLNAGO, Cláudio de Oliveira Santos; PEDRA, Adriano Sant'Ana. Meio ambiente digital, arquitetura e direito de resposta: os deveres dos prestadores de serviços de internet. In: BAEZ, Narciso L. X.; STURMA, Pavel; MOZETIC, Vinicius A.; FAIX, Martin. (Org.). Mecanismos internacionais e internos de efetividade dos direitos fundamentais. 1. ed. Chapecó: Editora Unoesc, v. 1, p. 397-419, 2014.

COLNAGO, Cláudio de Oliveira Santos; PEDRA, Adriano Sant'Ana. Medio ambiente digital, arquitetura y derecho de réplica: las obligaciones de los proveedores de servicios de internet en virtud de la constitución brasileña. In: I ENCONTRO DE INTERNACIONALIZAÇÃO DO CONPEDI. 1, v. 8, 2014, Barcelona. Anais [...] Barcelona: Ediciones Laborum, 2015. p. 233-252.

COLNAGO, Cláudio de Oliveira Santos; PEDRA, Adriano Sant'Ana. Tutela de dados pessoais no Brasil e dever de desindexação na internet: potencialidade do habeas data para uma proteção adequada no meio ambiente digital. In: II CONGRESO MUNDIAL DE JUSTICIA CONSTITUCIONAL. 2015b. Anais [...]. 2015 b. <https://www.academia.edu/36422963/COLNAGO_COS_PEDRA_AS._Tutela_de _dados_pessoais_no_Brasil_e_dever_de_desindexa\%C3\%A7\%C3\%A3o_na_intern et>. Acessado em: 23 nov. 2018.

COLNAGO, Cláudio de Oliveira Santos; PEDRA, Adriano Sant'Ana. Los deberes de los proveedores de servicios de internet en el medio ambiente digital: el caso del derecho de réplica en el Brasil. Estudios Constitucionales, a. 14, n. 2, p. 347-364, 2016.

COSTA, Luís Otávio Monteiro; FABRIZ, Daury Cesar. Deveres fundamentais e soberania popular: a desobediência civil como mecanismo de participação democrática e promoção de direitos fundamentais. Revista Eletrônica de Direito e Política, Itajaí, n. 13, n. 1, 2018. 
DIMOULIS, Dimitri; MARTINS, Leonardo. Teoria geral dos direitos fundamentais. 3. ed. São Paulo: Revista dos Tribunais, 2011.

DUQUE, Bruna Lyra; PEDRA, Adriano Sant'Ana. Os deveres fundamentais e a solidariedade nas relações privadas. Revista de Direitos Fundamentais e Democracia, Curitiba, v. 14, n. 14, p. 147-161, jul./dez., 2013.

DUQUE, Bruna Lyra. Os deveres fundamentais e a solidariedade nas relações privadas. Revista de Direitos Fundamentais e Democracia, v. 14, n. 14, p. 147161, jul./dez., $2013 b$.

DUQUE, Bruna Lyra; PEDRA, Adriano Sant'Ana. Deveres fundamentais e justiça constitucional: um exame da liberalidade de expressão e da proteção da criança e do adolescente. 2015. Disponível em: <https://www.academia.edu/36422988/DUQUE_BL_PEDRA_AS._Deveres_funda mentais_e_justi\%C3\%A7a_constitucional_liberdade_de_express\%C3\%A3o_e_prot e\%C3\%A7\%C3\%A3o_da_crian\%C3\%A7a_e_do_adolescente>. Acessado em 23 nov. 2015.

FABRIZ, Daury Cesar; OBREGÓN, Marcelo Fernando Quiroga. O dever fundamental de proteção ambiental no mar territorial. Revista da Faculdade de Direito da UFMG, Belo Horizonte, n. 65, pp. 71-198, jul.dez., 2014.

FABRIZ, Daury Cesar; SILVA, Heleno Florindo da. O meio ambiente natural e a proteção integral das crianças: a educação ambiental como dever fundamental dos pais para a preservação das presente e futuras gerações. Quaestio Iuris, Rio de Janeiro, v. 9, 2016.

FABRIZ, Daury Cesar; SILVA, Heleno Florindo da. Os deveres fundamentais e a desobediência civil em democracias de baixíssima intensidade: aproximações e distanciamentos a partir da ilegitimidade de um governo. SGARBOSSA, Luís Fernando; IENSUE, Geziela. (Orgs.). Estudos em teoria do estado e constitucional. Campo Grande: Instituto Brasileiro de Pesquisa Jurídica, 2018.

FAORO, Julio Pinheiro. Administração pública, financiamento e concretização dos direitos fundamentais. Revista de Direito Brasileira, n. 3, 2012.

FAORO, Julio Pinheiro. Deveres como condição para a concretização de direitos. Revista de Direito Constitucional e Internacional, São Paulo, a. 20, v. 79, abr.jun., 2012b. 
FAORO, Julio Pinheiro. Solidariedade e justiça fiscal: uma perspectiva diferente sobre a concretização de direitos a partir do dever de pagar impostos. Revista de Direito Constitucional e Internacional, a. 20, v. 81, out./dez., 2012c.

FAORO, Julio Pinheiro. Um conceito de dignidade humana (II): um ponto de encontro - uma pequena teoria sobre os direitos e deveres fundamentais. Revista do Instituto do Direito Brasileiro, a. 1, n. 5, 2012d.

FAORO, Julio Pinheiro. Justiça fiscal e solidariedade: deveres fundamentais e a concretização de direitos fundamentais. II Congresso Brasileiro de Filosofia do Direito - Justiça Fiscal, Orçamento e Efetivação dos Direitos Fundamentais. Belo Horizonte. 27 - 31 de agosto de 2012e.

FAORO, Julio Pinheiro. Políticas públicas, deveres fundamentais e concretização de direitos. Revista Brasileira de Políticas Públicas, v. 3, n. 2, jul./dez., 2013.

FAORO, Julio Pinheiro. Deveres fundamentais: uma revisão de literatura. Direitos fundamentais e jurisdição constitucional: análise, crítica e contribuições. 1. ed. São Paulo: Editora Revista dos Tribunais, 2014.

FONSECA, Bruno Gomes Borges da; LEITE, Carlos Henrique Bezerra. A paralisação da atividade econômica como um dos efeitos do dever fundamental de proteção do meio ambiente do trabalho pelo empregador. Espaço Jurídico Jornal of Law, Chapecó, v. 16, n. 1, 2015.

FREIJEDO, Franciso J. Bastida. Prólogo y laudatio. SÁNCHEZ, Ana Bada [et al]. La obra judicial de Francisco Rubio Llorente. Oviedo: Universidad de Oviedo, 1994.

GALANTE, Elisa Helena Lesqueves; PEDRA, Adriano Sant'Ana. O dever fundamental de proteção ao meio ambiente correspectivo ao direito fundamental de propriedade e o dever estatal de indenizar quando a intervenção por limitação administrativa afeta o conteúdo econômico da propriedade. Derecho y Cambio Social, Lima, a. 11, n. 36, 2014.

GONÇALVES, Luísa Cortat Simonetti. Empreendedorismo particular e dever fundamental de diagnosticar e planejar: uma análise no contexto jurídico brasileiro. Revista de Direito Ambiental. v. 89, jan./mar. 2018.

GONÇALVES, Luísa Cortat Simonetti; FABRIZ, Daury César. A medida do binômio necessidade-possibilidade no dever fundamental dos descendentes de proverem os ascendentes. Derecho y cambio social, a. 10, n. 31, 2013. 
GONÇALVES, Luísa Cortat Simonetti; FABRIZ, Daury César. Dever fundamental: a construção de um conceito. DE MARCO; Christian Magnus; PEZZELLA, Maria Cristina Cereser; STEINMETZ, Wilson (Orgs.). Teoria geral e mecanismos de efetividade no Brasil e na Espanha. Série Direitos fundamentais civis. 1. t. pp. 87-96. Joaçaba: Editora Unoesc, 2013 b.

GONÇALVES, Luísa Cortat Simonetti; PEDRA, Adriano Sant'Ana. Deveres fundamentais: a ressocialização enquanto dever do próprio apenado. In.: BUSSINGER, Elda Coelho de Azevedo (Org.). Direitos fundamentais: pesquisas. 1. ed. Curitiba: CRV, 2011.

GUEDES, João Bernardo Antunes de; FABRIZ, Daury Cesar. Dever fundamental de cooperação em processos administrativos da autoridade marítima: possibilidade de aplicação subsidiária do CPC no que tange à má-fé. Revista de Direito Público, Londrina, v. 12, n. 13, p. 115-152, dez. 2017.

HOMEM DE SIQUEIRA, Julio Pinheiro Faro. Mínimo existencial e o dever de pagar tributos ou financiando os direitos fundamentais. Revista da Academia Brasileira de Direito Constitucional, Curitiba, v. 1, n. 1, ago./dez., 2009.

HOMEM DE SIQUEIRA, Julio Pinheiro Faro. Um debate esquecido sobre políticas públicas: a importância dos deveres para a eficácia dos direitos. In.: CONPEDI. Anais do XX Encontro Nacional do CONPEDI. Florianópolis: Fundação Boiteux, 2011.

LACERDA, Ludmila Lais Costa; FARO, Julio Pinheiro. Direito como integridade e integridade do meio ambiente: o dever fundamental de proteção do meio ambiente e a proposta interpretativa de Dworkin a partir da jurisprudência do STF e do STJ. ULHOA, Paulo Roberto; FARO, Júlio Pinheiro. (Coords.). Direitos humanos e meio ambiente: obra dedicada ao Instituto Terra. Vitória, Cognorama, 2014.

LACERDA, Ludmila Lais Costa; FARO, Julio Pinheiro. Direito como integridade e integridade do meio ambiente: o dever fundamental de proteção do meio ambiente e a proposta interpretativa de Dworkin a partir da jurisprudência do STF e do STJ. Revista Brasileira de Direito Constitucional, a. 22, v. 89, out./dez., 2014 b.

LANCHESTER, Fulco. Los deberes constitucionales em el derecho comparado. Revista de Derecho Constitucional Europeo, v. 7, n. 13, 2010.

LARANJA, Anselmo Laghi; FABRIZ, Daury Cesar. O dever fundamental de obedecer às leis e a Desobediência Civil: uma análise do art. 33 da Declaração 
Americana dos Direitos e Deveres do Homem. Revista Brasileira de Estudos Políticos, Belo Horizonte, n. 117, pp. 127-157, jul./dez., 2018.

LLORENTE, Francisco Rubio. Los deberes constitucionales (1). Revista Española de Derecho Constitucional, a. 21, n. 62, maio/ago., 2001.

MACHADO, Álvaro Augusto Lauff; PEDRA, Adriano Sant'Ana. A redução das alíquotas do IPI incidente na comercialização de veículos automotores: uma (in)justificável relativização do dever fundamental de contribuir com os gastos públicos. Direitos e deveres fundamentais. Rio de Janeiro: Editora Lumen Juris, 2012.

MACHADO, Álvaro Augusto Lauff; PEDRA, Adriano Sant'Ana. Redução de alíquota do imposto sobre produtos industrializados para automóveis: reflexões sobre uma sociedade (in)sustentável, o princípio da seletividade tributária e o dever fundamental de pagar tributos. Revista da AJURIS, v. 40, n. 130, jun. 2013.

. O dever fundamental de pagar tributos em debate: uma análise de imposto de renda sobre os proventos de aposentadoria ou reforma percebidos por portadores de neoplasia maligna. Derecho y Cambio Social, a. 11, n. 37, 2014.

MARQUES, Fabiano Lepre; FABRIZ, Daury Cesar. Breves considerações sobre deveres com sanção e deveres sem sanção no direito brasileiro. Derecho y cambio social, a. 10, n. 31, 2013.

NABAIS, José Casalta. A face oculta dos direitos fundamentais: os deveres e os custos dos direitos. Revista Direito Makenzie, v. 3, n. 2, 2002.

NABAIS, José Casalta. Nota sobre o dever fundamental de pagar tributos. In.: ALLEMAND, Luiz Cláudio Silva (Coord). Direito tributário: questões atuais. Brasília: Conselho Federal da OAB, 2012.

OBREGÓN, Marcelo Fernando Quiroga; FABRIZ, O dever fundamental de proteção ambiental no mar territorial e nas águas interiores áreas portuárias poluição por derramamento de água de lastro. Derecho y Cambio Social, a. 12, n. 41, 2015.

PECES-BARBA MARTÍNEZ, Gregório. Los deberes fundamentales. Doxa. n. 4, p. 1987.

PEDRA, Adriano Sant'Ana. A importância dos deveres humanos na efetivação de 
direitos. In: ALEXY, Robert. [et al.]. (Orgs.). Níveis de efetivação dos direitos fundamentais civis e sociais: um diálogo Brasil e Alemanha. Joaçaba: Editora Unoesc, 2013.

PEDRA, Adriano Sant'Ana. Les devoirs fondamentaux de la personne et la protection des droits sociaux: un abordage des coûts des droits dans la perspective de la solidarité. 2014. Disponível em: <https://www.academia.edu/36423032/PEDRA_AS._Les_devoirs_fondamentaux_d e_la_personne_et_la_protection_des_droits_sociaux>. Acessado em: 23 nov. 2018.

PEDRA, Adriano Sant'Ana. Los deberes de las personas y la realización de los derechos fundamentales. Estudios Constitucionales, a. 12, n. 2, 2014b.

PEDRA, Adriano Sant'Ana. Solidariedade e deveres fundamentais da pessoa humana. In.: GALUPP, Marcelo [et al.] (Eds.). Human rights, rule of law and the contemporary social challenges in complex societies: proceedings of the XXVI World Congress of Philosophy of Law and Social Philosophy of the Internationale Vereinigunf für Rechts- und Sozialphilosophie. Belo Horizonte: Initia Via, 2015.

PEDRA, Adriano Sant'Ana. Deveres fundamentais e sua previsão em tratados internacionais firmados pelo Brasil. 2015b. Disponível em: <https://fdv.academia.edu/DeveresFundamentaisFDV>. Acessado em: 23 nov. 2018.

PEDRA, Adriano Sant'Ana. O dever fundamental dos pais de educar os filhos: porque a educação necessita de esforços pessoais. In: MORAES, Daniela Marques de; LABONARSKI, Jaime Ruben Sapolinski. Direitos e garantias fundamentais II. Florianópolis: CONPEDI, 2016.

PEDRA, Adriano Sant'Ana; FREITAS, Rodrigo Cardoso. A função social da propriedade como um dever fundamental. Revista da Faculdade de Direito UFMG, Belo Horizonte, n. 66, pp. 53-74, jan./jun. 2015.

PEDRA, Anderson Sant'Ana; PEDRA, Adriano Sant'Ana. Dever fundamental de pagar tributos, omissão legislativa inconstitucional e deslocamento provisório da competência legislativa. In.: BUSSINGER, Elda Coelho de Azevedo. Direitos e deveres fundamentais. Rio de Janeiro: Lumen Juris, 2012.

PEREZ LUÑO, Antonio E. Los derechos fundamentales. 8. ed. Madrid: Tecnos, 2004.

protesto. PEDRA, Adriano Sant'Ana; GROBERIO, Sonia do Carmo. Manifestações contra as normas de trânsito injustas e as de risco: desobediência civil?. Revista de 
Direito da Cidade, Rio de Janeiro, v. 10, n. 2, 2018.

SILVA, Heleno Florindo da. A família e o afeto: o dever fundamental dos pais em dar afeto aos filhos como mecanismo de proteção ao desenvolvimento da personalidade e concretização da dignidade humana. Nomos: Revista do Programa de Pós-Graduação em Direito da UFC, v. 32, n. 2, jul./dez., 2012.

SILVA, Heleno Florindo da; FABRIZ, Daury Cesar. O meio ambiente natural e a proteção integral das crianças: a educação ambiental como dever fundamental dos pais para a preservação das presentes e futuras gerações. Revista do Programa de Pós-Graduação em Direito da UFC, v. 35, n. 2, jul.dez., 2015.

SILVA, Heleno Florindo da; GONÇALVES, Suelen Florindo; FABRIZ, Daury César. A proteção integral e prioritária à criança como dever fundamental dos pais: uma análise a partir da relação entre pais fumantes e seus filhos. Revista do Programa de Pós-Graduação em Direito da UFC, v. 34, n. 1, jan./jun., 2014.

SILVA, Rodrigo Monteiro da; PEDRA, Adriano Sant'Ana. Transparência nas audiências públicas ambientais como instrumento de maximização ao dever fundamental de proteção ao meio ambiente. Revista Brasileira de Estudos Políticos, Belo Horizonte, n. 112, pp. 271-298, jan./jun. 2016.

SILVA, Rodrigo Monteiro da; PEDRA, Adriano Sant'Ana. Alienação antecipada de bens em processos de apuração de atos de improbidade administrativa: uma abordagem a partir do dever fundamental de colaboração com a justiça. Revista de Processo, a. 42, v. 267, maio. 2017.

SIMÕES, Sandro Nery; FABRIZ, Daury César. O dever fundamental de preservação do meio ambiente cultural e a liberdade. Derecho y Cambio Social, a. 12, n. 41, 2015.

SIQUEIRA, Julio Pinheiro Faro Homem de. Deveres fundamentais e constituição brasileira. Revista de filosofia do direito, do Estado e da Sociedade, Natal, v. 1, n. 2, ago./dez. 2010.

SIQUEIRA, Julio Pinheiro Faro Homem de. Los deberes fundamentales y la constitución brasileña. Revista de Direitos e Garantias Fundamentais, Vitória, n. 9, 2011.

SIQUEIRA, Julio Pinheiro Faro Homem de; FABRIZ, Daury Cesar. Os deveres e a eficácia dos direitos fundamentais. In: BUSSINGER, Elda Coelho de Azevedo. (Orgs.). Direitos fundamentais: pesquisas. Curitiba: CRV, 2011. 
SIQUEIRA, Julio Pinheiro Faro Homem de. Elementos para uma teoria dos deveres fundamentais: uma perspectiva jurídica. Revista de Direito Constitucional e Internacional, v. 95, abr./jun. 2016.

SIQUEIRA, Julio Pinheiro Faro Homem de. Administración pública, realización financiación de los derechos fundamentales. In: ALCALÁ, J. Alberto del Real. (Eds.). La maquinaria del derecho en Iberoamérica: constituición, derechos fundamentales y administración. Ciudad de México: Editorial Flores, 2016b.

TAVARES, Henrique da Cunha; PEDRA, Adriano Sant'Ana. As obrigações tributárias acessórias e a proporcionalidade na sua instituição: uma análise a partir da teoria dos deveres fundamentais. Revista Tributária e de Finanças Públicas, a. 21, v. 109, mar./abr., 2013.

TAVARES, Henrique da Cunha; PEDRA, Adriano Sant'Ana. A eficácia dos deveres fundamentais. Derecho y Cambio Social, Lima, a. 11, n. 37, 2014.

TAVARES, Henrique da Cunha; PEDRA, Adriano Sant'Ana. Accessory tax obligations from the perspective of the fundamental duties theory. In: GALUPP, Marcelo [et al.] (Eds.). Human rights, rule of law and the contemporary social challenges in complex societies: proceedings of the XXVI World Congress of Philosophy of Law and Social Philosophy of the Internationale Vereinigunf für Rechts- und Sozialphilosophie. Belo Horizonte: Initia Via, 2015.

VELLO, Renata Pinho Coelho; PEDRA, Adriano Sant'Ana. O dever fundamental de testemunhar: uma análise de sua eficácia horizontal. In: BUSSINGER, Elda Coelho de Azevedo (Orgs.). Direitos fundamentais: pesquisas. p. 201-208. Curitiba: Editora CRV, 2011.

VIEIRA, Pedro Gallo; PEDRA, Adriano Sant'Ana. O rol de deveres fundamentais na Constituição como numerus apertus. Derecho y Cambio Social, a. 10, n. 31, 2013.

Data da submissão: 01/03/2019

Data da primeira avaliação: 15/05/2019

Data da segunda avaliação: 16/08/2019

Data da aprovação: 16/08/2019 